\title{
The Significant Role of Solid Oxide Interphase in Enhancement of Cycling Performance of Sn Thin-Film Anodes
}

\author{
K.-F. Chiu, ${ }^{a, z}$ H. C. Lin, ${ }^{a}$ K. M. Lin, ${ }^{\text {b }}$ T. Y. Lin, ${ }^{a}$ and D. T. Shieh ${ }^{\mathrm{c}}$ \\ ${ }^{a}$ Department of Materials Science and Engineering, Feng Chia University, 407 Taichung, Taiwan \\ ${ }^{b}$ Department of Materials Science and Engineering, National Taiwan University, Taipei, Taiwan \\ ${ }^{c}$ Materials Research Laboratory, Industrial Technology Research Institute, Hsinchu, Taiwan
}

Sn thin-film anodes have been prepared by radio-frequency magnetron sputtering with additional anode shielding on the sputter gun. The anode shielding effectively reduced kinetic energy of the adatoms during deposition, and the deposited thin films were $\mathrm{X}$-ray amorphous and exhibited fine and smooth morphology with nanoparticles $(5-10 \mathrm{~nm})$ uniformly dispersed on the surface. By changing the charge-discharge scheme and deliberately depositing a $\mathrm{SnO}_{2}$ surface coating, the properties of the solid electrolyte interphase of these anodes can be modulated. The cycling properties of the $\mathrm{Sn}$ thin films with deliberate $\mathrm{SnO}_{2}$ surface coating are significantly improved.

(c) 2006 The Electrochemical Society. [DOI: 10.1149/1.2189246] All rights reserved.

Manuscript submitted September 30, 2005; revised manuscript received February 6, 2006. Available electronically April 11, 2006.

Lithium-ion secondary batteries are thus far the most promising power sources for portable electronic products. Recently, a new class of anode materials, lithium alloys, has been considered for alternative anode materials ${ }^{1-3}$ because of high-capacity storage, which is twice as high as commercial carbonaceous anodes for lithium-ion batteries. Among the lithium alloy anode materials, metal $\mathrm{Sn}$ has been reviewed and investigated in detail. ${ }^{4-6}$

However, there are still some drawbacks for the lithium alloy anodes which hinder their application. For Sn anodes, the high degree of volume expansion/contraction during lithium insertion/ removal into/from the host matrix during charge-discharge cycles of batteries often induces huge mechanical stress, resulting in the loss of reversible capacity. It has been reported that reducing the particle $s^{2} \mathrm{e}^{2}$ or the thickness of anode layers ${ }^{7}$ can decrease the simultaneously induced stress and thus enhance the cycle life. From this point of view, nanocrystalline or amorphous materials are most suitable for alloy-type anodes. Mao et al. ${ }^{8}$ reported the development of Sn-based nanocomposite anodes by mechanical grinding and alloying, which showed low initial capacity loss and good cycling properties. In 2005, Sony Corporation announced a newly developed Sn-based amorphous anode ${ }^{9}$ consisting of multiple elements such as $\mathrm{Sn}, \mathrm{Co}, \mathrm{C}$, which effectively reduced the shape changes during charge-discharge cycles. In addition, it is well known that the solid electrolyte interphase $^{10,11}$ (SEI) plays a key role. The properties of the SEI layer, capping on the surface of the anodes, significantly influence the electrochemical properties such as capacity loss, reversibility, and energy efficiency. Different Sn-related composite or intermetallic compounds result in different SEI and interface reactions ${ }^{12,13}$ and have been viewed as potential candidates for anodes of lithium-ion batteries. ${ }^{12-14}$ In these material systems, the drastic volume changes could be buffered by inactive elements such as $\mathrm{Li}_{2} \mathrm{O}$. The flexible inactive elements stabilized the films of the anodes during charge-discharge cycles and therefore the cycling performance could be improved. In addition, a recent study by Kim et al. ${ }^{15}$ has revealed the capping effect of oxide coatings on Sn-based anodes, which effectively reduced the surface cracks and improved the stability of the anodes.

In this study, Sn thin films were deposited by an anode-shieldingassisted magnetron-sputtering technique. Thin-film Sn anodes with nanosized surface features (particles) were obtained. The electrochemical properties of the deposited films were evaluated by halfcell charge-discharge cycling and cyclic voltammetry (CV) tests. The properties of SEI were modified by using a suitable chargedischarge scheme and a deliberately deposited ultrathin surface cap-

${ }^{\text {z } E-m a i l: ~ k f c h i u @ f c u . e d u . t w ~}$ ping layer $\left(\mathrm{SnO}_{2}\right)$. The electrochemical properties of the thin-film $\mathrm{Sn}$ anodes have been significantly improved by the surface SEI and oxide coatings.

\section{Experimental}

The Sn thin films were prepared by radio frequency (rf) magnetron sputtering and deposited on p-type $\mathrm{Si}(100)$ wafers or stainless steel substrates using a 2-in.-diam pure Sn (99.99\%) target. Figure 1 shows the setup of our sputter system. The dimensions of the additional anode shielding have been shown in a previous paper. ${ }^{16}$ The $\mathrm{rf}$ gun power was $40 \mathrm{~W}$. The distance between target and substrate was $8.5 \mathrm{~cm}$. The working gas for deposition was $\operatorname{Ar}(99.99 \%$ purity), and total gas flow was set at $15 \mathrm{sccm}$ during sputtering. The working pressure was maintained at $1.33 \mathrm{~Pa}$ during deposition. By controlling the deposition time, all Sn films described here have the same thickness of $\sim 120 \mathrm{~nm}$, measured by an $\alpha$-step profilometer (Veeco Instruments, Inc., Dektak 3030ST). The mass of the Sn films was obtained by multiplying the mass deposition rate $\left(\mathrm{mg} / \mathrm{s} \mathrm{cm}^{2}\right)$ with deposition time. Bulk density $\left(\mathrm{Sn} 7.31 \mathrm{~g} / \mathrm{cm}^{3}\right)$ was assumed for the measurement of mass deposition rates. However, because the actual film density varies with deposition conditions, the capacities $(\mathrm{mAh} / \mathrm{g})$ are therefore subject to an uncertainty of $\pm 5 \%$.

The film crystallography was characterized by grazing-angle X-ray diffraction (XRD) using a Rigaku D/MAX2500 X-ray diffractometer with $\mathrm{Cu} \mathrm{K} \alpha$ radiation (wavelength $1.5405 \AA$ ). The surface morphology was observed by a JEOL JSM-6700 field emission scanning electron microscope (FESEM). The electrochemical tests, including charge-discharge, $\mathrm{CV}$, and cycle life tests, were performed using Autolab PGSTAT30 and Jeihan 5000 potentiostat/galvanostat systems. Half-cells based on films prepared under different conditions were tested. Lithium metal was used as counter and reference electrodes, and the electrolyte was $1 \mathrm{M} \mathrm{LiPF}_{6}$ and ethylene carbonate (EC) ethylmethyl carbonate (EMC) (volume ratio 1:2) solution. The half-cells were charged (lithiated) and discharged (delithiated) using a current of 50 and $10 \mu \mathrm{A} \mathrm{cm}^{-2}$ (current per unit surface of stainless steel substrate), respectively, with different voltage cutoff ranges, $0.05-1.00$ and $0.05-2.50 \mathrm{~V}$, at a constant temperature of $25^{\circ} \mathrm{C}$. The larger charge current density $\left(50 \mu \mathrm{A} \mathrm{cm}^{-2}\right)$ at initial lithiated state prevents the occurrence of anomalous irreversible capacity and avoids the decomposition of electrolyte. ${ }^{5}$ Typically for 120-nm-thick Sn films, the first charge took $\sim 2 \mathrm{~h}$. The charging current of $50 \mu \mathrm{A} \mathrm{cm}^{-2}$ corresponded to $429 \mathrm{~mA} \mathrm{~g}^{-1}$. All cells were assembled and tested in an Ar-filled glove box. A layer of ultrathin $\mathrm{SnO}_{2}(20 \mathrm{~nm})$ was also deposited on top of Sn thin films using a pure $\mathrm{SnO}_{2}(99.99 \%)$ target to modulate the SEIs. The electrochemical properties of the $\mathrm{SnO}_{2}$-coated and uncoated $\mathrm{Sn}$ thin-film electrodes were studied and compared. The cells were labeled as AS 


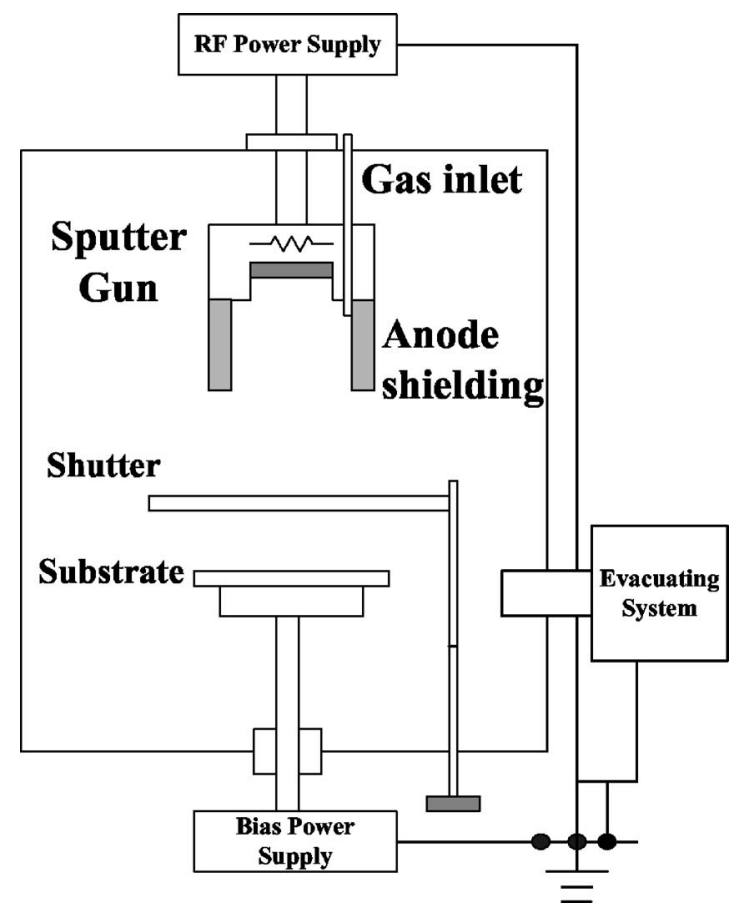

Figure 1. Schematic diagram of anode-shielding-assisted magnetron sputter system.

(Sn thin films cycled within $0.05-2.50 \mathrm{~V}$ ), AS-1 (Sn thin films cycled within $0.05-1.0 \mathrm{~V})$, and $\mathrm{SnO}_{2} / \mathrm{AS}-1\left(\mathrm{SnO}_{2}\right.$-coated $\mathrm{Sn}$ thin films cycled within $0.05-1.0 \mathrm{~V}$ ).

\section{Results and Discussion}

It has been reported in other literature ${ }^{6,17}$ that Sn particles diffuse easily on the surface of the substrate and therefore have a strong tendency to form large clusters during deposition. However, the additional anode shielding has been shown to be an effective way to reduce the particle sizes of $\mathrm{Sn}$ thin films as reported in our previous work. ${ }^{13}$ Figure 2 shows the surface morphology of Sn thin films deposited with the anode shielding (labeled AS) sputtering technique. The surface morphology of thin films are smooth and composed of nanosized primary particles $(5-10 \mathrm{~nm})$. The anode shield-

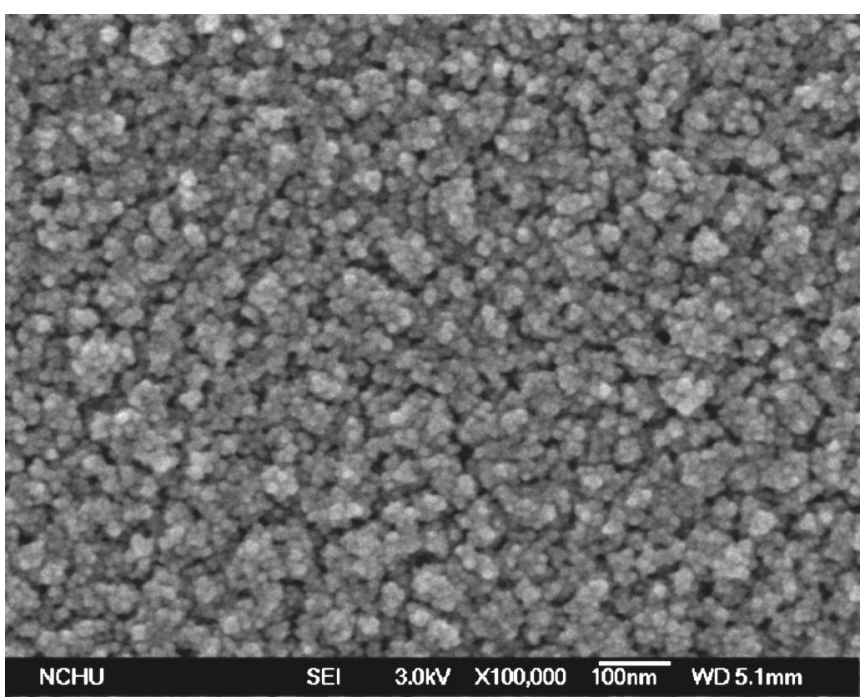

Figure 2. Surface morphology of deposited Sn thin films.
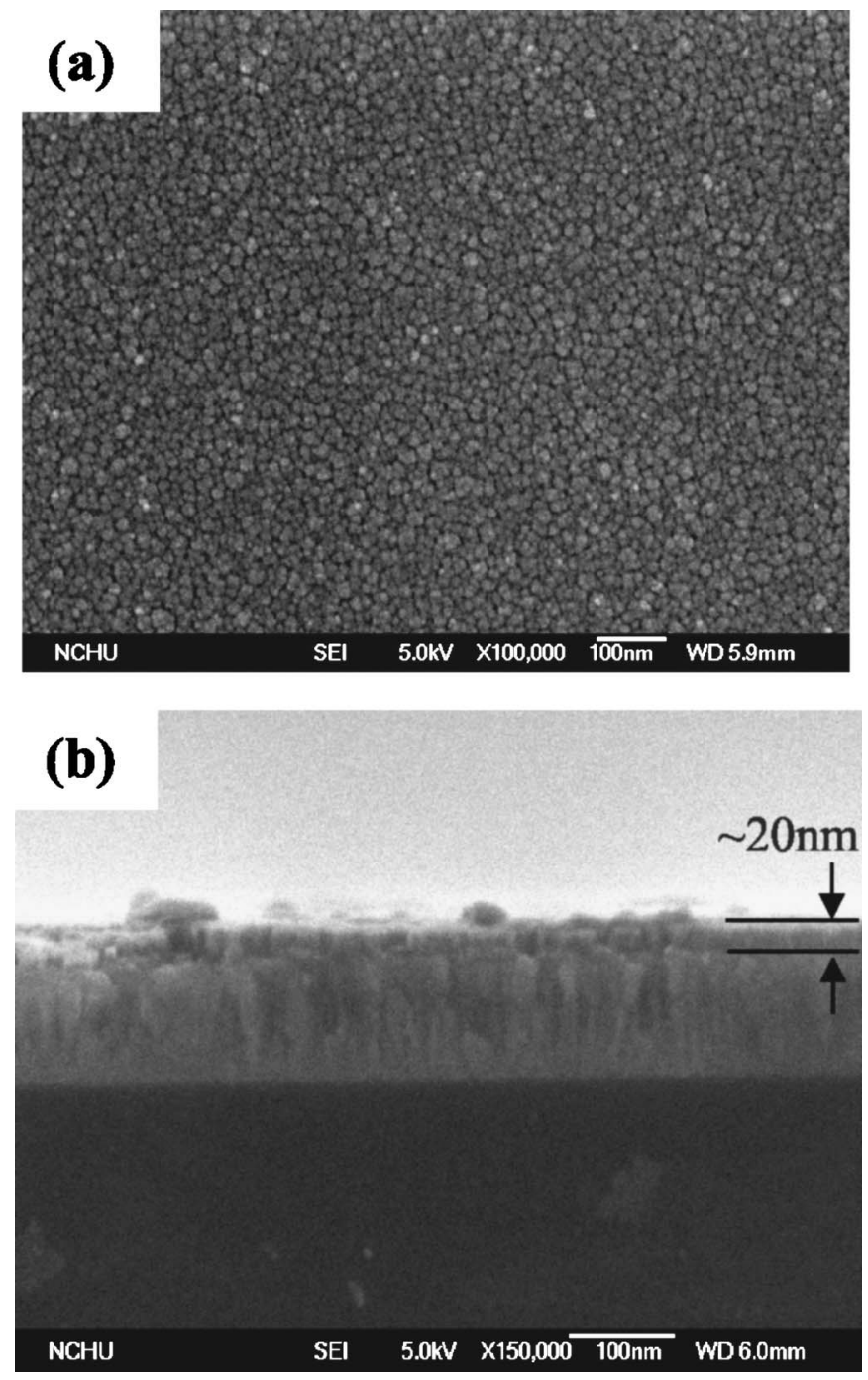

Figure 3. SEM images of composite $\mathrm{SnO}_{2} / \mathrm{AS}$ cells: (a) surface morphology and (b) cross section.

ing confined the plasma, resulting in lower ion flux on the substrate holder. As a consequence, Sn particles during deposition cannot gain enough energy to agglomerate and thus result in ultrasmall particle size. The AS films with $\mathrm{SnO}_{2}$ surface coating also display similar morphology, as shown in Fig. 3a and b. The thickness of $\mathrm{SnO}_{2}$ layer was about $20 \mathrm{~nm}$ thick and the total thickness of the $\mathrm{SnO}_{2} / \mathrm{AS}$ bilayer was about $140 \mathrm{~nm}$.

Figure 4 shows the XRD patterns of $\mathrm{AS}$ and $\mathrm{SnO}_{2} / \mathrm{AS}$ thin films. Both types of films exhibit low-intensity diffraction peaks and show near-amorphous features, corresponding to the nanosized surface morphologies shown in Fig. 3 and 4. The grain size (AS film in Fig. 4) estimated by Scherrer's equation is around $3 \mathrm{~nm}$.

Half-cells made of the Sn thin films deposited with anode shielding were cycled between different cutoff voltage ranges, 2.50-0.05 and 1.00-0.05 V (labeled as AS and AS-1, respectively), and the composite anodes, $\mathrm{SnO}_{2} / \mathrm{AS}$ thin films, were also tested. The electrochemical properties and cycle life performances of these thin films are detailed in Table I and shown in Fig. 5.

As shown in Table I, the initial capacity $(1248 \mathrm{mAh} / \mathrm{g})$ for the cell with $\mathrm{SnO}_{2} / \mathrm{AS}-1$ bilayers thin film is higher than the pure metal AS-1 cell $(997 \mathrm{mAh} / \mathrm{g})$ and lower than the pure $\mathrm{SnO}_{2}$ cell (1746 mAh/g), as expected for a composite electrode. This means that the $\mathrm{SnO}_{2}$ surface coating layer of $20 \mathrm{~nm}$ also contributes to the cell capacity. Comparison of the AS, AS-1, and $\mathrm{SnO}_{2} / \mathrm{AS}-1$ cells 


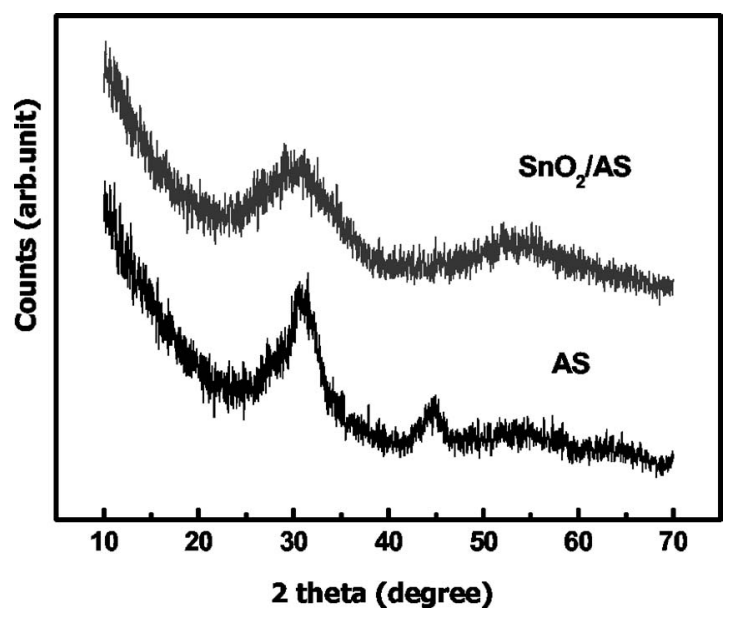

Figure 4. XRD patterns of $\mathrm{AS}$ and composite $\mathrm{SnO}_{2} / \mathrm{AS}$ thin films.

shows that the $\mathrm{SnO}_{2} / \mathrm{AS}-1$ film exhibits higher irreversible capacity loss because additional lithium is consumed by the $\mathrm{SnO}_{2}$ layer and forms $\mathrm{Li}_{2} \mathrm{O}$ on the surface during the first cycle.

A relatively lower initial capacity loss of $13.11 \%$ can be obtained for the AS cells. As the cycle number increases, the capacity of the AS samples decreases. The reversible capacity decreases quickly to $522 \mathrm{mAh} / \mathrm{g}$ up to 20 cycles and then decays to $398 \mathrm{mAh} / \mathrm{g}$ after 80 cycles. Changing the cutoff voltage to $1.0 \mathrm{~V}$, the AS- 1 cell with the same surface morphology and the same particle size does not show the same results in cycling ability compared to AS cell. As shown in Fig. 5, the AS-1 cell shows lower capacity initially and retains higher reversible capacity than AS cell in early cycles (569 $\mathrm{mAh} / \mathrm{g}$ at cycle 20 ). However, as the cycle number exceeds 30 , the reversible capacity of the AS-1 cell rapidly decays again and is as low as $257 \mathrm{mAh} / \mathrm{g}$ after 80 cycles.

The AS and AS-1 cells were prepared in the same sputtering run and assembled in the same conditions and time. However, these cells show obviously different cycling performances, as seen in Fig. 5. In the initial stage of the cycle test, the capacity retained well for the AS- 1 cell compared to the AS cell. It is supposed for the AS- 1 cell that variation in volume due to lithiation/delithiation processes are relatively small compared to the AS cell. However, the AS cell is cycled in a large potential range $(2.50-1.00 \mathrm{~V})$ and may undergo more severe volume changes, which can result in cracks and the loss of electric contact between Sn particles and film/substrate interfaces. Therefore, the reversible capacity of the AS cell $(522 \mathrm{mAh} / \mathrm{g})$ fades quickly and is lower than that of the AS-1 cell $(569 \mathrm{mAh} / \mathrm{g})$ in the first 20 cycles. Surprisingly, as both samples are cycled beyond 20 cycles, the capacity of the AS-1 cell decreases dramatically. It is possible that the SEI is responsible for this different performance. Figure $6 \mathrm{a}$ and $\mathrm{b}$ shows the $\mathrm{CV}$ curves of both cells scanned at $0.2 \mathrm{mV} / \mathrm{s}$. We can observe the reduction peak above $1.00 \mathrm{~V}$ and the differences between the first sweep and subsequent sweeps in AS

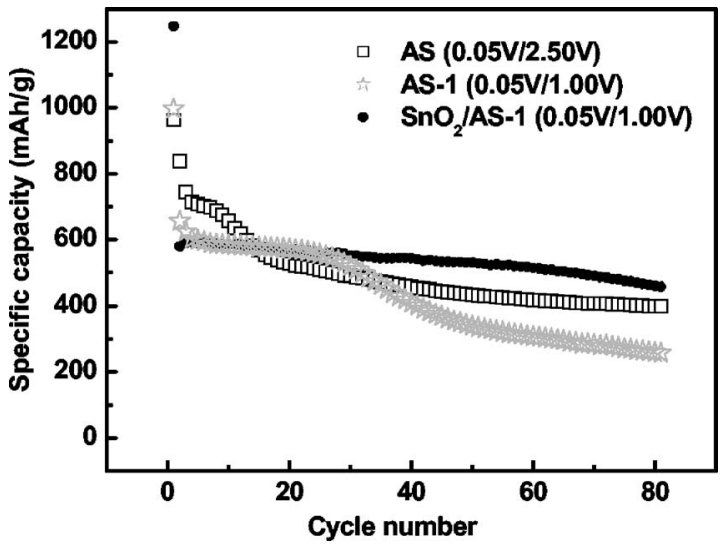

Figure 5. Cycling tests of $\mathrm{AS}, \mathrm{AS}-1, \mathrm{SnO}_{2} / \mathrm{AS}-1$ cells.

and AS-1 cells. It is well known that there is no formation of $\mathrm{Li}_{x} \mathrm{Sn}$ phases above $0.8 \mathrm{~V}$ for $\mathrm{Sn}$ electrodes. ${ }^{1,3}$ Hence, we suppose that there is SEI formation at around $1.37-1.50 \mathrm{~V}$ and that this is the critical point which affects the stability of the AS-1 cells in the cycling test. In Fig. 6a, low intensities of reduction peaks at approximately $1.27 \mathrm{~V}$ can be still found for AS cells at the second sweep. It is the typical phenomenon for the lithium alloy anodes. The lithium alloy anodes suffer from severe volume changes and cracks at the first charge-discharge and subsequent cycles. The completion of SEI formation takes several charge-discharge cycles. ${ }^{18}$ In the cracked electrode, the new electrochemically active Sn particles are exposed to the electrolyte. Consequently, more and thicker SEI layers are formed after several cycles and then help to fully cover the surface of the Sn thin film. This thick SEI serves as a flexible capping layer, which increases the integrity of the films and thus enhances the endurance of following volume changes. As a result, the AS cell shows better cycling performance and good capacity retention in long cycling tests. For the AS-1 cell, there are only mild volume changes initially. Therefore, the SEI layers are thinner and do not cover the film surface as well. As the stress accumulates after more than 20 cycles, the film severely cracks. Because the thin SEI layer is not able to hold the cracked films, film peel-off may readily occur.

Figure $7 \mathrm{a}$ and $\mathrm{b}$ shows the XRD patterns of AS and AS- 1 cells after 80 cycles (at $0.05 \mathrm{~V}$ ). The XRD samples are prepared in an argon-filled glove box and then rinsed with electrolyte to clean the precipitates of the lithium compound formed after cycling. We can observe the near-amorphous Sn peak centred near $31^{\circ}$ with wide full width at half-maximum (fwhm) for both AS and AS-1 films as shown in Fig. 7, which corresponds to the Sn peak shown in Fig. 4. For the AS-1 film, this characteristic peak is sharper than the AS film, by comparing the fwhm values, possibly indicating that the Sn particles agglomerate after 80 cycles. For the AS cell with a well-capped SEI layer, the Sn peak shows a much lower intensity,

Table I. Electrochemical performances of the Sn thin films deposited under different conditions. ${ }^{\text {a }}$

\begin{tabular}{|c|c|c|c|c|c|c|}
\hline Samples & $\begin{array}{c}\text { Cutoff voltage } \\
\text { (V) }\end{array}$ & $\begin{array}{c}\text { Initial } \\
\text { charge } \\
\text { capacity } \\
(\mathrm{mAh} / \mathrm{g} \pm 5 \%)\end{array}$ & $\begin{array}{c}\text { Initial } \\
\text { efficiency } \\
(\%)\end{array}$ & $\begin{array}{c}\text { Discharge } \\
\text { capacity } \\
\text { at cycle } 1 \\
(\mathrm{mAh} / \mathrm{g} \pm 5 \%)\end{array}$ & $\begin{array}{c}\text { Discharge } \\
\text { capacity } \\
\text { at cycle } 20 \\
(\mathrm{mAh} / \mathrm{g} \pm 5 \%)\end{array}$ & $\begin{array}{c}\text { Discharge } \\
\text { capacity } \\
\text { at cycle } 50 \\
(\mathrm{mAh} / \mathrm{g} \pm 5 \%)\end{array}$ \\
\hline AS & $2.50-0.05$ & 963 & 86 & 828 & 522 & 432 \\
\hline AS-1 & $1.00-0.05$ & 997 & 65 & 624 & 569 & 335 \\
\hline $\mathrm{SnO}_{2} / \mathrm{AS}-1$ & $1.00-0.05$ & 1248 & 46 & 589 & 570 & 528 \\
\hline $\mathrm{SnO}_{2}^{\mathrm{a}}$ & $1.00-0.05$ & 1746 & 38 & 663 & - & - \\
\hline
\end{tabular}

${ }^{a}$ This cell is for comparison, and no cycling test was performed. 

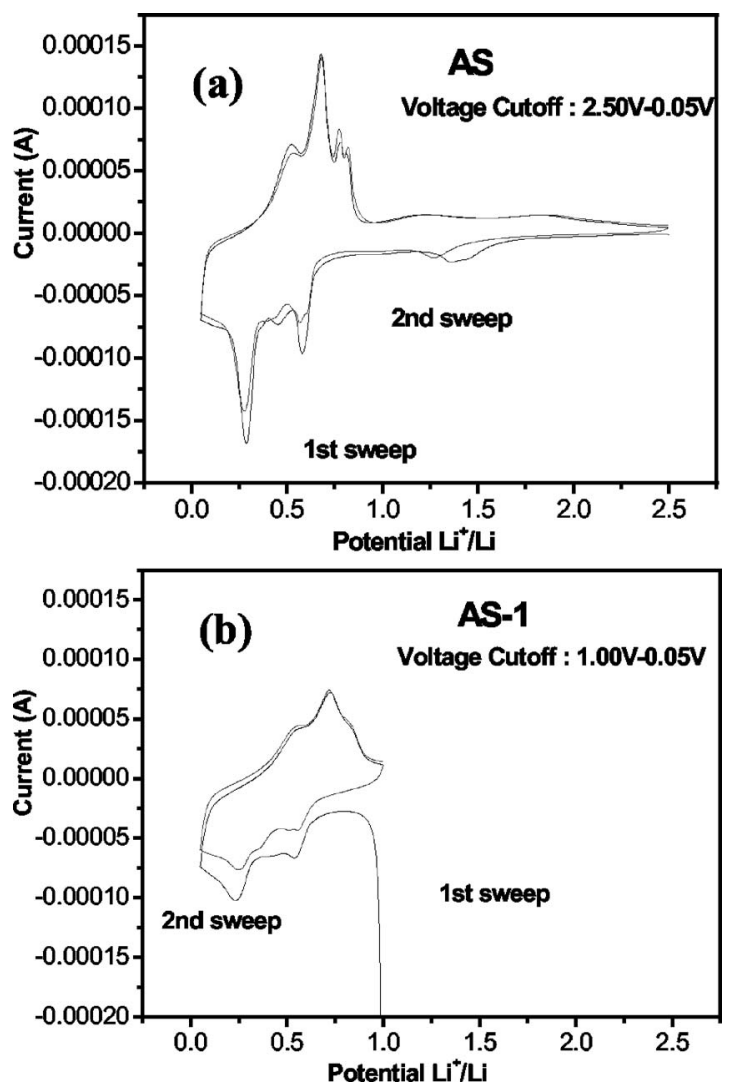

Figure 6. $\mathrm{CV}$ s of the sputtered $\mathrm{Sn}$ thin films swept between (a) 2.50-0.05 and (b) $1.00-0.05 \mathrm{~V}$ (scan rate $0.20 \mathrm{mV} \mathrm{s}^{-1}$ ).

indicating that the thicker SEI layer of the AS film may buffer the Sn particles and therefore prevent the agglomeration on the film surface.

Both films show characteristic peaks of $\mathrm{Li}_{x} \mathrm{Sn}$ alloys, as seen in Fig. 7a and b. For the AS film, the diffraction peaks corresponding to $\mathrm{Li}_{2.6} \mathrm{Sn}, \mathrm{Li}_{3.5} \mathrm{Sn}$, and $\mathrm{Li}_{4.4} \mathrm{Sn}$ are detected. However, for AS-1 film, only highly lithiated peaks, $\mathrm{Li}_{3.5} \mathrm{Sn}$ and $\mathrm{Li}_{4.4} \mathrm{Sn}$, are detected. This indicates that the lithiation degree of the AS film is lower than the AS-1 film, because low lithium content phase $\mathrm{Li}_{2.6} \mathrm{Sn}$ is detected only in the AS film. These results may be attributed to the wellcapped SEI layer for the AS film, which hinders the transportation of $\mathrm{Li}$ ions and reduces the degree of lithiation.

However, it is difficult to identify the structure and electrochemical properties of a SEI layer. Therefore, the deliberately deposited ultrathin $\mathrm{SnO}_{2}$ layer may serve as an artificial SEI layer. Interestingly, the $\mathrm{SnO}_{2} / \mathrm{AS}-1$ cell shows the best cycling ability among the three cells. Despite the fact that it is also cycled in the cutoff voltage range of $0.05-1.00 \mathrm{~V}$, the $\mathrm{SnO}_{2} / \mathrm{AS}-1$ cell shows the highest reversible capacity. After the initial capacity loss reversible capacity of $\sim 589 \mathrm{mAh} / \mathrm{g}$ with near $100 \%$ capacity retention can be achieved for up to 20 cycles, and it still has a capacity of over $450 \mathrm{mAh} / \mathrm{g}$ after 80 cycles.

As reported in the literature, ${ }^{13,14}$ the amorphous $\mathrm{Li}_{2} \mathrm{O}\left(\mathrm{a}-\mathrm{Li}_{2} \mathrm{O}\right)$ can be well-formed and held under $1.3 \mathrm{~V}$ for the $\mathrm{SnO}_{2}$ films. It is possible that this a- $\mathrm{Li}_{2} \mathrm{O}$ SEI and the remaining $\mathrm{SnO}_{2}$ serve as a protection layer, stabilizing the AS-1 cell. As a result, the cell can endure or prevent cracking and crumbling. It also stops the active $\mathrm{Sn}$ thin films from reacting with the electrolyte. The well-capped $\mathrm{SnO}_{2} / \mathrm{AS}-1$ cells show much better capacity retention than AS-1 cells, and in fact, the highest capacity retention up to 80 cycles among the tested cells. Hence, we can conclude that the cycling
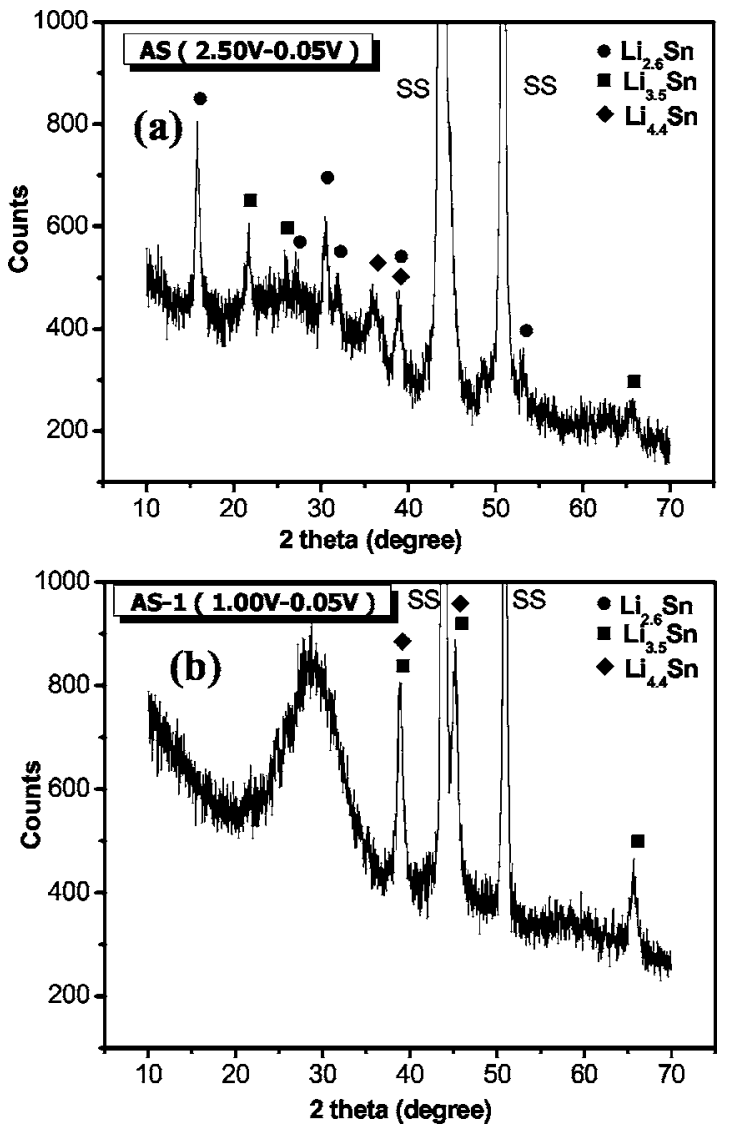

Figure 7. XRD patterns of $\mathrm{Sn}$ thin films after 80 cycles between (a) $2.50-0.05 \mathrm{~V}$ (AS) and (b) $1.00-0.05 \mathrm{~V}$ (AS-1). The films were fully charged (lithiated) to $0.05 \mathrm{~V}$.

performance of Sn thin-film electrodes may be improved effectively by using a suitable charge-discharge scheme or by coating a suitable capping layer (i.e., passivation layer).

\section{Conclusions}

Nanosized Sn thin films were deposited using rf sputter deposition with additional anode shielding equipped on the sputter gun. It has been demonstrated that producing an appropriate SEI protection layer, by cycling in the $2.50-0.05 \mathrm{~V}$ range, or depositing a surface capping layer can effectively improve the cycling properties. For $\mathrm{Sn}$ films with a smooth and fine surface under a well-capped $\mathrm{SnO}_{2}$ layer, reversible capacity can be significantly improved.

\section{Acknowledgments}

This research work was sponsored by Taiwan R.O.C. National Science Council under contract no. NSC 92-2216-E-035-024 and NSC 93-2216-E-035-024.

Feng Chia University assisted in meeting the publication costs of this article.

\section{References}

1. M. Winter and J. O. Besenhard, Electrochim. Acta, 45, 31 (1999).

2. J. Yang, M. Winter, and J. O. Besenhard, Solid State Ionics, 90, 281 (1996).

3. R. A. Huggins, J. Power Sources, 81/82, 13 (1999).

4. L. Y. Beaulieu, S. D. Beattie, T. D. Hatchard, and J. R. Dahn, J. Electrochem. Soc., 150, A419 (2003).

5. S. D. Beattie, T. D. Hatchard, A. Bonakdarpour, K. C. Hewitt, and J. R. Dahn, $J$. Electrochem. Soc., 150, A701 (2003).

6. L. Y. Beaulieu, T. D. Hatchard, A. Bonakdarpour, M. D. Fleischauer, and J. R. Dahn, J. Electrochem. Soc., 150, A1457 (2003).

7. J. O. Besenhard, J. Yang, and M. Winter, Abstracts of the 8th International Meeting on Li Batteries, Nagoya, Japan, p. 96 (1996).

8. O. Mao, R. L. Turner, I. A. Courtney, B. D. Fredericksen, M. I. Buckett, L. J 
Krause, and R. J. Dahn, Electrochem. Solid-State Lett., 2, 3 (1999).

9. K. Ogisu, Portable Power 2005 Conference, San Francisco, CA (2005).

10. E. Peled, J. Electrochem. Soc., 126, 2047 (1979).

11. E. Peled, in Lithium Batteries, J.-P. Gabano, Editor, p. 43, Academic Press, New York (1983).

12. I. A. Courtney and J. R. Dahn, J. Electrochem. Soc., 144, 2045 (1997).

13. I. A. Courtney and J. R. Dahn, J. Electrochem. Soc., 144, 2943 (1997).

14. Y. Idota, T. Kubota, A. Matsufuji, Y. Maekawa, and T. Miyasaka, Science, 276, 1395 (1997).

15. T. J. Kim, D. Son, J. Cho, B. Park, and H. Yang, Electrochim. Acta, 49, 4405
(2004).

16. K.-F. Chiu, H. C. Lin, K. M. Lin, T. Y. Lin, and D. T. Shieh, J. Electrochem. Soc., Submitted (2005).

17. L. Y. Beaulieu, K. C. Hewitt, R. L. Turner, A. Bonakdarpour, A. A. Abdo, L. Christensen, K. W. Eberman, L. J. Krause, and J. R. Dahn, J. Electrochem. Soc. 150, A149 (2003).

18. K. Zaghib, K. Tatsumi, H. Abe, H. Sakaebi, S. Higuchi, T. Ohsaki, and Y. Sawada, Abstract 581, The Electrochemical Society Meeting Abstracts, Vol. 94-1, San Fransisco, CA, May 22-27, 1994. 